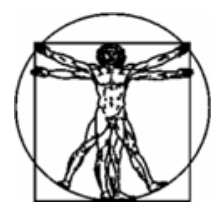

\title{
ОЦЕНКА ИЗМЕНЕНИЯ НАПРЯЖЕННО-ДЕФОРМИРОВАННОГО СОСТОЯНИЯ ГЛАЗА И ПОКАЗАТЕЛЕЙ ВНУТРИГЛАЗНОГО ДАВЛЕНИЯ ПОСЛЕ РЕФРАКЦИОННОЙ КОРРЕКЦИИ ГИПЕРМЕТРОПИИ
}

\author{
С.М. Бауэр ${ }^{1}$, Л.А. Венатовская ${ }^{1}$, Д.В. Франус ${ }^{1}$, Л.А. Федотова ${ }^{2}$ \\ ${ }^{1}$ Кафедра теоретической и прикладной механики Санкт-Петербургского государственного университета, \\ Россия, 198504, Санкт-Петербург, Университетский проспект, 28, e-mail: s_bauer@mail.ru, \\ I karamshina@mail.ru, franus@mavis.ru \\ г Чебоксарский филиал ФГУ “МНТК “Микрохирургия глаза” им. акад. С.Н. Федорова” Минздрава России, \\ Россия, 428028, Чебоксары, Проспект тракторостроителей, 10, e-mail: lar.fedotova@mail.ru
}

\begin{abstract}
Аннотация. Проводится анализ влияния параметров удаляемого при коррекции гиперметропии методами LASIK и IntraLASIK кольцевого слоя на изменение напряженно-деформированного состояния роговицы. Упругая система роговицасклера представляется в виде двух сопряженных трансверсально-изотропных сфрерических сегментов, нагруженных внутренним давлением. Для оценки изменения показателей внутриглазного давления, получаемых аппланационными тонометрами Гольдмана и Маклакова после операций по коррекции гиперметропии, рассматривается задача о деформации роговицы под действием груза с плоским основанием. Проводится сравнение результатов двух различных операций и сравнение двух методов измерения внутриглазного давления для каждой из этих операций при одном истинном внутриглазном давлении. В результате моделирования получено, что изменение толщины роговицы за счет удаления кольцевого слоя при операциях по коррекции гиперметропии, как и в случае коррекции миопии, приводят к уменьшению изгибной жесткости роговицы, а, следовательно, к уменьшению показателей внутриглазного давления, получаемых апланационными тонометрами Гольдмана и Маклакова. По данным расчетов, изменение показателей внутриглазного давления зависит и от внутреннего и от внешнего радиуса удаляемого кольцевого слоя, глубины зоны абляции, а также толщины формируемого роговичного лоскута. При этом изменения показателей внутриглазного давления, полученные с помощью тонометра Маклакова, существенно меньше изменений получаемых тонометром Гольдмана. Численные расчеты показали преимущество рефракционных операций по коррекции гиперметропии, выполняемых методом IntraLASIK, по сравнению с методом LASIK. Так как при операциях LASIK удаляется кольцевой слой меньшего диаметра и срезается более толстая роговичная крышка, в результате данной коррекции наблюдаются большие деформации и смещения в области утончения роговицы, а также большее снижение изгибной жесткости роговицы.
\end{abstract}

Ключевые слова: внутриглазное давление, гиперметропия, аппланационная тонометрия, операция LASIK, операция IntraLASIK.

\footnotetext{
(C) Бауэр С.М., Венатовская Л.А., Франус Д.В., Федотова Л.А., 2015
}

Бауэр Светлана Михайловна, д.ф.-м.н., профессор кафедры гидроупругости, Санкт-Петербург

Венатовская Людмила Александровна, к.ф.-м.н., доцент кафедры теоретической и прикладной механики, Санкт-Петербург

Франус Дмитрий Валерьевич, аспирант кафедры теоретической и прикладной механики,

Санкт-Петербург

Федотова Лариса Александровна, врач-хирург офтальмолог высшей квалификационной категории,

Чебоксары 


\section{ВВЕДЕНИЕ}

Гиперметропия является одной из самых распространенных и сложных аномалий оптической системы глаза, на долю которой в общей структуре рефракционных патологий приходится около $40 \%[1,2,12]$. В настоящее время для лечения гиперметропии широко используется кераторефракционная хирургия, одной из задач которой является поиск эффективного и безопасного метода коррекции зрения со стабильным эффектом $[11,12]$. В ряде работ отмечается, что лечение гиперметропии, при всем многообразии существующих способов ее коррекции, отстает от лечения миопии по эффективности, безопасности, прогнозируемости и стабильности получаемых результатов $[2,9,11,12]$.

На сегодняшний день одним из наиболее эффективных методов коррекции различных аномалий рефракции считается лазерный кератомилез in situ (LASIK). Операция LASIK заключается в формировании роговичного лоскута (flap) механическим микрокератомом с последующей эксимерлазерной абляцией (испарением) роговицы. Однако при коррекции гиперметропии лазерная абляция идет не в центре, как при коррекции миопии, а ближе к периферии роговицы, что приводит к определенным трудностям при выкраивании лоскута достаточного диаметра для проведения оптимальной по параметрам операции [9]. На точность выкраивания роговичного лоскута влияют не только характеристики кератома, лезвия и уровень вакуума во время операции, но и исходные параметры роговицы [9]. Использование механического микрокератома приводит к неравномерности выкраиваемых лоскутов, толщина которых в центре получается меньше, чем на периферии [12].

В последнее десятилетие начали использовать новый вид операций IntraLASIK, которые проводятся по методу $L A S I K$, но для формирования роговичного лоскута используется безлезвенный фемтосекундный кератом. В отличие от других типов лазеров, фемтосекундный лазер воздействует не на внешнюю поверхность роговицы, а на средние слои (строму), минуя верхние слои (эпителий и боуменову мембрану). Фемтосекундный лазер создает в роговице идеальную круговую полость, состоящую из крошечных кавитационных пузырьков, формируя тем самым лоскут абсолютно любой формы с высочайшей точностью по глубине воздействия и по диаметру [9]. Таким образом, использование фемтосекундного лазера позволяет проводить операцию ближе к периферии, что в значительной степени улучшает рефракционные и функциональные результаты у пациентов с гиперметропией [12].

Целью данной работы является построение конечно-элементной модели в программном пакете ANSYS, позволяющей оценить изменения напряженнодеформированного состояния роговицы и показателей внутриглазного давления после рефракционных операций по коррекции гиперметропии: LASIK (Laser-assisted in situ keratomileusis - «лазерный кератомилез») и IntraLASIK (Introstromal laser in situ keratomileusis).

\section{МАТЕРИАЛЫ И МЕТОДЫ}

Для оценки напряженно-деформированного состояния роговицы предложена конечно-элементная модель, в которой, как и в работах $[3,4]$, роговица и склера представляются сопряженными сферическими сегментами с разными радиусами $R_{c}$ и $R_{s}$ и разными упругими свойствами (рис. 1). Предполагается, что составная оболочка заполнена несжимаемой жидкостью с давлением $p$. При моделировании учитывается различие толщин и упругих свойств основных слоев роговицы: эпителия $\left(L_{1}\right)$, боуменовой оболочки $\left(L_{2}\right)$, стромы $\left(L_{3}\right)$ и десцементовой оболочки $\left(L_{4}\right)$. Склера моделируется однородным сегментом большего радиуса $\left(L_{5}\right)$. 

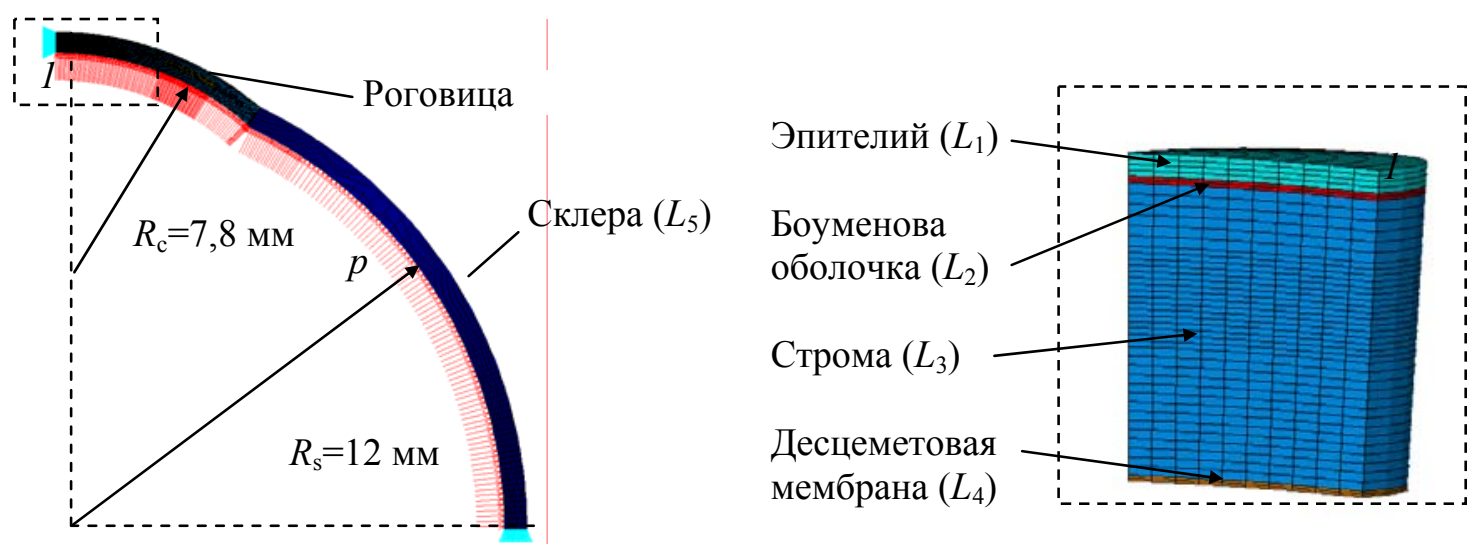

Рис. 1. Модель сопряженных трансверсально-изотропных оболочек
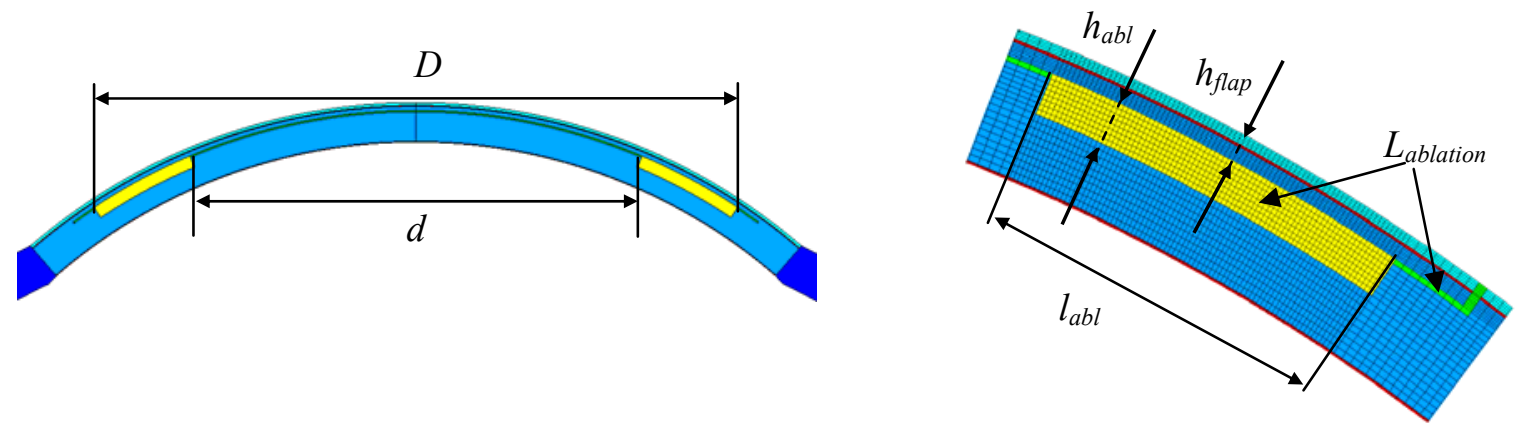

Рис. 2. Параметры удаляемого при операциях $L A S I K$ и IntraLASIK слоя роговичной ткани

Согласно клиническим данным [12], полагается, что при LASIK лазерным лучом удаляется кольцевой слой $\left(L_{\text {ablation }}\right)$ роговичной ткани с внутренним диаметром $d$ от 6,0 до 6,2 мм и внешним диаметром $D$ от 8,5 до 8,75 мм; при IntraLASIK удаляется кольцевой слой той же ширины $l_{a b l}$, но с большими внутренним от 6,4 до 6,6 мм и внешним от 9,2 до 9,4 мм диаметрами. Толщина срезаемого при операциях роговичного лоскута $-h_{\text {flap }}$, глубина удаляемого кольцевого слоя $-h_{a b l}$ (рис. 2 ). Срез роговичного лоскута также моделируется слоем $L_{\text {ablation}}$.

По данным [5, 6], склера и роговица близки к трансверсально-изотропным оболочкам, поэтому, при моделировании на упругие коэффициенты роговицы и склеры накладываются следующие ограничения [10]:

$$
\left|v_{i}^{\prime}\right|<\left(E_{i}^{\prime} / E_{i}\right)^{1 / 2} ;-1<v_{i}<1-2\left(v_{i}^{\prime}\right)^{2}\left(E_{i} / E_{i}^{\prime}\right) ;\left(E_{i}>0, E_{i}^{\prime}>0\right) ; i=1, \ldots, 5,
$$

где $E_{i}$ и $E_{i}^{\prime}$ - модули упругости при растяжении-сжатии на поверхности изотропии и в направлении перпендикулярном к ней; $v_{i}$ и $v_{i}^{\prime}-$ коэффициенты Пуассона; $G$ и $G^{\prime}-$ модули сдвига для плоскости изотропии и плоскости, перпендикулярной к ней, $G=E / 2\left(1+v_{i}\right)$.

В результате лазерной коррекции существенно уменьшается толщина роговицы, в связи с чем отмечается необходимость правильной интерпретации показателей внутриглазного давления у пациентов, перенесших рефракционные операции [7].

Для оценки изменения показателей внутриглазного давления после операций по коррекции гиперметропии исследуется деформация роговицы под действием груза с плоским основанием, т.е. рассматривается модель аппланационных тонометров Маклакова и Гольдмана (рис. 3). 


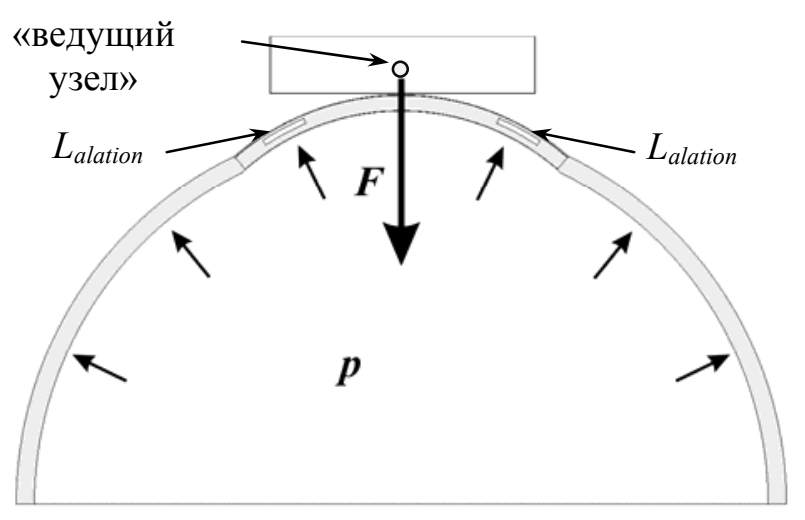

Рис. 3. Модель аппланационного тонометра

При измерении внутриглазного давления тонометром Маклакова на роговицу глаза помещается груз с плоским основанием весом 10 г. Под действием груза роговица деформируется, при этом регистрируется диаметр площади контакта груза с роговицей. Тонометр Гольдмана измеряет силу, которую необходимо приложить для сплющивания фиксированной центральной области роговицы. Уплощенная область должна быть диаметром 3,06 мм, так как при такой зоне контакта нагрузка в 0,1 г соответствует внутриглазному давлению, равному 1 мм рт. ст., таким образом, сила (г) умножается на десять и находится внутриглазное давление.

Измерение внутриглазного давления тонометрами Маклакова и Гольдмана моделируется контактными задачами в программном пакете ANSYS. С точки зрения математики решается прямая и обратная задача при одной механической модели. В первом случае к штампу прикладывается сила $F$, равная 10 г $(0,1 \mathrm{H})$, и фиксируется площадка контакта. Во втором случае, величина силы давления груза варьируется таким образом, чтобы зона контакта составляла 3,06 мм. На каждом шаге нагружения роговицы проверяется условие постоянства внутреннего объема.

При построении конечно-элементной модели рассматривается осесимметричная задача. В силу симметрии выполняется двумерное моделирование (2D) с использованием в качестве конечного элемента PLANE182. При моделировании используются контактные элементы «поверхность-поверхность» для создания жесткоподатливого контакта между поверхностями тонометра и роговицы. Жесткая целевая поверхность тонометра связывается с так называемым «ведущим узлом», к которому прикладывается сила давления груза $F$ (рис. 3).

\section{РезУЛЬтатЫ}

Расчеты проводились для различных параметров срезаемого роговичного лоскута и удаляемого в результате рефракционных операций кольцевого слоя роговичной ткани. Зависимость показателей внутриглазного давления от упругих свойств и геометрических параметров роговицы и склеры была показана ранее в работах $[3,4,6]$.

Толщины $h$ и упругие коэффициенты основных слоев роговицы, склеры и слоя абляции приведены в таблице. Модули упругости каждого слоя роговицы в направлении толщины оболочки $E^{\prime}$ принимались в 20 раз меньше тангенциальных модулей $E[5,6]$, а средний модуль упругости роговицы принимался на порядок меньше модуля упругости склеры. Коэффициенты Пуассона роговицы, склеры и слоя абляции на поверхности изотропии принимались равными $v=0,49$, в направлении толщины $\nu^{\prime}=0,01$; коэффициенты сдвига $G=0,1, G^{\prime}=0,9$. 
Значения толщины и упругих коэффициентов роговицы, склеры и слоя абляции

\begin{tabular}{|c|c|c|c|c|c|c|}
\hline \multirow[b]{2}{*}{ Параметр } & \multicolumn{4}{|c|}{ Роговица } & \multirow[b]{2}{*}{ Склера } & \multirow{2}{*}{$\begin{array}{c}\text { Слой } \\
\text { абляции }\end{array}$} \\
\hline & Эпителий & $\begin{array}{c}\text { Боуменова } \\
\text { оболочка }\end{array}$ & Строма & $\begin{array}{c}\text { Десцементова } \\
\text { оболочка }\end{array}$ & & \\
\hline$h, \mathrm{Mм}$ & 0,04 & 0,012 & 0,5 & 0,01 & 0,6 & $0,017 \div 0,172$ \\
\hline$E$, МПа & 0,06 & 0,6 & 0,3 & 0,9 & 5,0 & $0,001 \div 0,0001$ \\
\hline$E^{\prime}, \mathrm{M \Pi а}$ & 0,003 & 0,03 & 0,015 & 0,045 & 0,5 & $0,01 \div 0,001$ \\
\hline
\end{tabular}
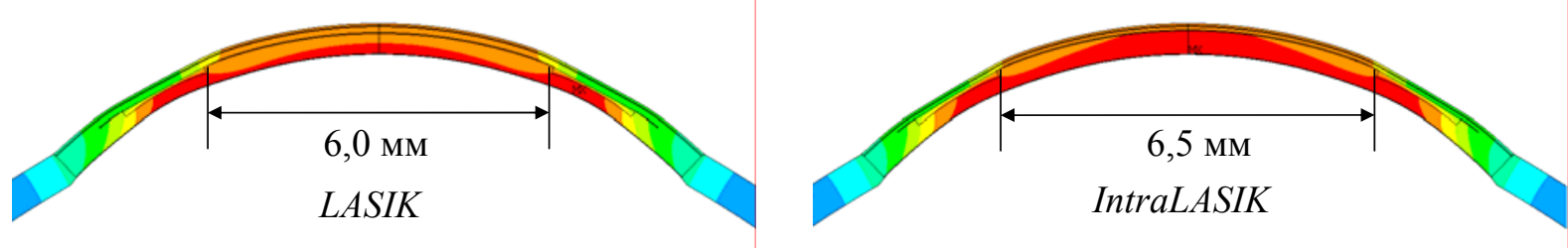

Рис. 4. Деформированная роговица после операций $L A S I K$ и IntraLASIK
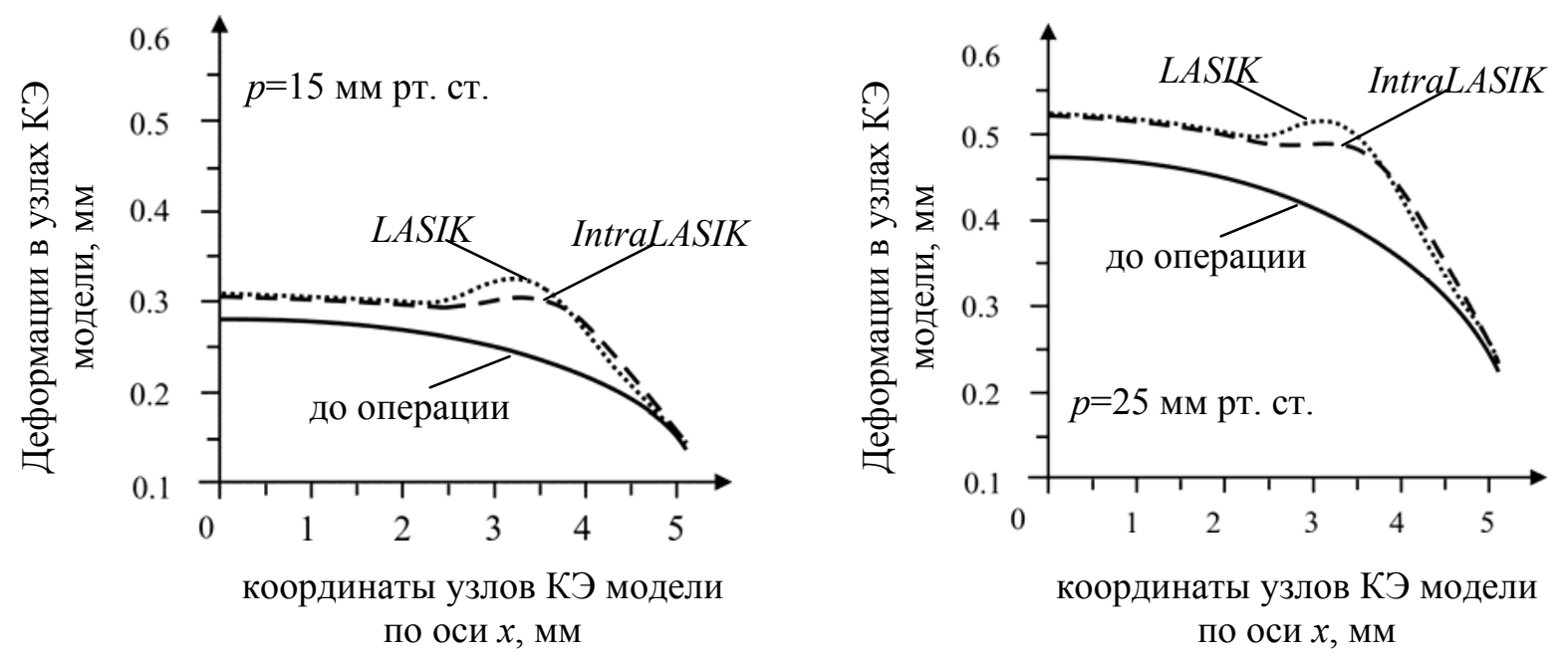

Рис. 5. Значения деформаций в узлах модели нижней поверхности роговицы до и после операций (КЭ - конечно-элементный)

На рис. 4 представлены контуры деформированной роговицы после операций $L A S I K$ и IntraLASIK. Внутренний диаметр удаляемого кольца (зоны абляции) при LASIK составляет 6,0 мм, при IntraLASIK - 6,5 мм. Ширина зоны абляции $l_{a b l}$ равна 1,375 мм, глубина $h_{a b l}$ составляет 172 мкм [3]. Толщина роговичного лоскута $h_{\text {flap }}$ принимается 160 мкм при операции LASIK и 110 мкм - при IntraLASIK. Истинное внутриглазное давление на представленном рисунке - 15 мм рт. ст.

На рис. 5 показаны значения деформаций в узлах конечных элементов внутренней поверхности роговицы до и после операций LASIK и IntraLASIK при величине внутриглазного давления 15 и 25 мм рт. ст.

Расчеты, проведенные для различных параметров срезаемого роговичного лоскута и удаляемого в результате рефракционных операций слоя роговичной ткани, показали, что после операций IntraLASIK роговица деформируется более равномерно, 


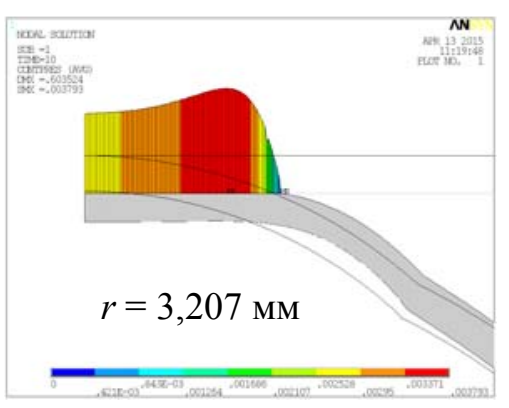

$a$

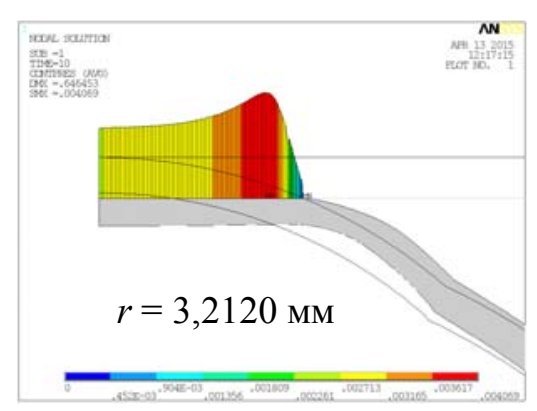

$\sigma$

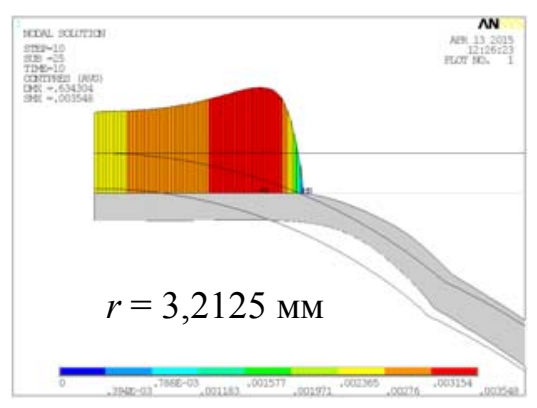

B

Рис. 6. Распределение контактных напряжений при измерении внутриглазного давления тонометром Маклакова (груз 10 г): $a$ - до коррекции гиперметропии; $\sigma$ - после коррекции методом LASIK ( $h_{\text {flap }}=160$ мкм); в - после коррекции методом IntraLASIK $\left(h_{\text {flap }}=110\right.$ мкм)

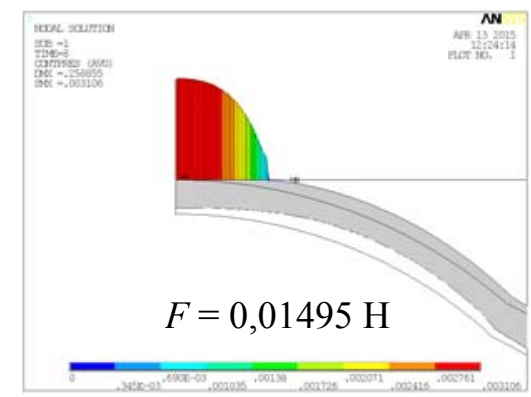

$a$

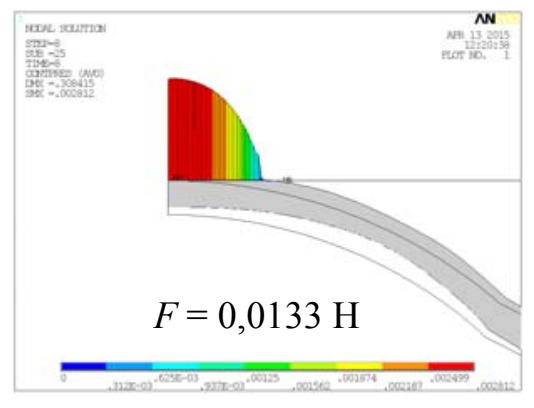

$\sigma$

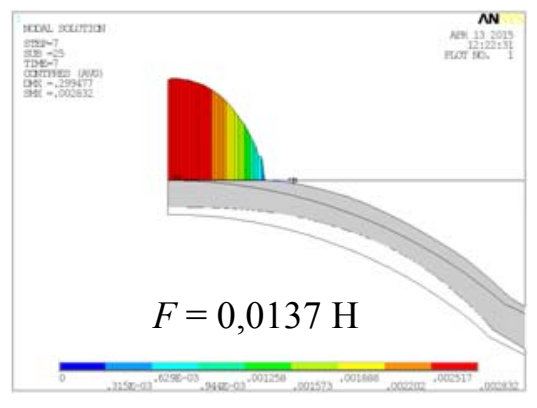

B

Рис. 7. Распределение контактных напряжений при измерении внутриглазного давления тонометром Гольдмана: $a$ - до коррекции гиперметропии; $\sigma$ - после коррекции методом $L A S I K\left(h_{\text {flap }}=160\right.$ мкм $) ;$ в - после коррекции методом IntraLASIK $\left(h_{\text {flap }}=110\right.$ мкм $)$

чем после LASIK. После операции LASIK наблюдаются большие деформации и смещения в области утончения роговицы, что объясняет более низкие рефракционные показатели, получаемые в клинической практике [12].

На рис. 6, 7 приводятся распределения контактных напряжений, получаемые тонометрами Гольдмана и Маклакова (10 г) при измерении внутриглазного давления после операций LASIK и IntraLASIK. Глубина зоны абляции $h_{a b l}$ на представленных рисунках составляет 172 мкм, истинное внутриглазное давление (до нагружения) 15 мм рт. ст.

Известно, что аппланационная тонометрия по Маклакову измеряет не истинное внутриглазное давление, а тонометрическое, которое определяется соотношением $p_{t}=W / S$, где $W$ - вес прилагаемого груза (или прикладываемая сила), $S$ - площадь зоны контакта [8]. Таким образом, тонометрическое давление, получаемое тонометром Маклакова, до операций составляет 22,75 мм рт. ст., после $L A S I K-22,679$ мм рт. ст., после IntraLASIK - 22,672 мм рт. ст. Данные результаты соответствуют истинному внутриглазному давлению 15,3 мм рт. ст.

В аппланационной тонометрии по Гольдману нагрузка в 0,1 г соответствует внутриглазному давлению, равному 1 мм рт. ст., поэтому истинное внутриглазное давление определяем как отношение $F / g$. Результаты расчетов, представленные на рис. 7, соответствуют 15,3 мм рт. ст. до лазерной коррекции, 13,6 мм рт. ст. после $L A S I K$ и 14,0 мм рт. ст. после InraLASIK.

В результате моделирования получено, что изменение толщины роговицы за счет удаления кольцевого слоя при операциях по коррекции гиперметропии, как и в 
случае коррекции миопии, приводит к уменьшению изгибной жесткости роговицы, а, следовательно, к уменьшению показателей внутриглазного давления, получаемых апланационными тонометрами Гольдмана и Маклакова. По данным расчетов, изменение показателей внутриглазного давления зависит и от внутреннего и от внешнего радиуса удаляемого кольцевого слоя, глубины зоны абляции, а также толщины формируемого роговичного лоскута. При этом изменения показателей внутриглазного давления, полученные с помощью тонометра Маклакова, существенно меньше изменений, получаемых тонометром Гольдмана. Показания тонометра Гольдмана оказываются более чувствительными к любым изменениям в геометрических параметрах роговицы, что соответствует результатам клинического исследования [7]. Данный факт необходимо учитывать при интерпретации тонометрических показателей у пациентов, перенесших рефракционную коррекцию.

\section{Выводы}

Численные расчеты показали преимущество рефракционных операций по коррекции гиперметропии, выполняемых методом IntraLASIK, по сравнению с методом $L A S I K$. Так как при операциях LASIK удаляется кольцевой слой меньшего диаметра и срезается более толстая роговичная крышка, в результате данной коррекции наблюдаются большие деформации и смещения в области утончения роговицы, а также большее снижение изгибной жесткости роговицы, что согласуется с клиническими данными [12]. При измерении внутриглазного давления тонометром Гольдмана показатели внутриглазного давления после $L A S I K$ за счет меньшей изгибной жесткости роговицы будут меньше, чем после операции IntraLASIK. При измерении внутриглазного давления тонометром Маклакова, за счет больших площадок контакта, возможно частичное перекрытие тонометром области утоньшения роговицы, в то время как при InraLASIK изгибу подвергается вся узкая область роговицы, показатели внутриглазного давления после $L A S I K$ могут быть незначительно выше показателей внутриглазного давления, получаемых тонометром после IntraLASIK.

\section{БЛАГОДАРНОСТИ}

Работа выполнена при поддержке гранта РФФИ № 15-01-06311-а.

\section{СПИСОК ЛИТЕРАТУРЫ}

1. Аветисов С.Э. Современные подходы к коррекции рефракционных нарушений // Вестник офтальмологии - 2006. - № 1. - С. 3-8.

2. Балашевич Л.И. Рефракционная хирургия. - СПб.: Издательский дом СПбМАПО, 2002. - 285 с.

3. Бауэр С.М., Карамшина Л.А., Качанов А.Б. Механические модели измерения внутриглазного давления тонометрами Маклакова и Гольдмана после операций по коррекции зрения // Российский журнал биомеханики. - 2012. - № 3 (57). - С. 25-31.

4. Бауэр С.М., Воронкова Е.Б. Модели теории оболочек и пластин в задачах офтальмологии // Вестник СПбГУ. Сер.1. - 2014. - Т. 1 (59), № 3. - С. 438-458.

5. Иомдина Е.Н. Механические свойства тканей глаза человека // Современные проблемы биомеханики. - 2006. - № 11. - С. 183-200.

6. Иомдина Е.Н., Бауэр С.М., Котляр К.Е. Биомеханика глаза: теоретические аспекты и клинические приложения. - М.: Реал Тайм, 2015. - 208 с.

7. Марченко Л. Н., Качан Т.В. Изменение показателей внутриглазного давления после эксимерлазерной коррекции аномалий рефракции // Офтальмология. Восточная Европа. - 2011. - № 4 (11). - С. $28-33$.

8. Нестеров А.П., Бунин А.Я., Кацнельсон Л.А. Внутриглазное давление. Физиология и патология. М.: Наука, 1974. -381 с. 
9. Патеева T.3., Паштаев Н.П. IntraLASIK и LASIK: особенности формирования роговичного лоскута у пациентов с плоской роговицей // Современные технологии катарактальной и рефракционной хирургии - 2011: Сб. науч. статей / ФГУ «МНТК «Микрохирургия глаза». - М., 2011. - 472 с.

10. Родионова В.А., Титаев Б.Ф., Черных К.Ф. Прикладная теория пластин и оболочек. СПб.: Изд-во С.-Петерб. ун-та, 1996. - 278 с.

11. Семенов Н.А., Дога А.В., Руднева М.А. ЛАЗИК в коррекции гиперметропии на российской эксимерлазерной сканирующей установке «Микроскан» // Офтальмохирургия. - 2005. - № 4. C. $13-15$.

12. Федотова Л.А., Куликова И.А. Преимущество лечения гиперметропии с использованием фемтосекундного лазера // Здравоохранение Чувашии. - 2009. - № 2. - С. 47- 50.

\title{
ESTIMATION OF CHANGES IN THE STRESS-STRAIN STATE OF AN EYE SHELL AND INTRAOCULAR PRESSURE READINGS AFTER REFRACTIVE CORRECTION OF HYPEROPIA
}

\author{
S.M. Bauer, L.A. Venatovskaya, D.V. Franus (Saint-Petersburg, Russia) \\ L.A. Fedotova (Cheboksary, Russia)
}

The influence of the parameters of annular layer which is removed in surgical LASIK and IntraLASIK correction of hyperopia on the changes of the stress-strain state of the cornea is analized. The elastic system cornea-sclera is presented as two conjugate transversely isotropic spherical segments loaded by internal pressure. In order to estimate changes of the intraocular pressure measurements obtained by Goldmann (GAT) and Maklakov (MAT) applanation tonometers after hyperopia surgery, the problem of deformation of the cornea under the load with a flat base is considered. A comparison of the results of two different operations and a comparison of two methods of measuring intraocular pressure for each of these operations is carried out using in all cases the same true intraocular pressure. As a result of the finite element simulation, it was found that reduction in the cornea thickness as a result of annular layer removing during hyperopia surgical correction reduces the flexural rigidity of the cornea and, as a consequence, leads to decrease in the intraocular pressure readings obtained by GAT and MAT. According to calculations, the changes in the intraocular pressure readings depend on the inner and outer diameters of the annular layer, on the depth of the ablation zone, and on the thickness of corneal flap. Nevertheless it was obtained than changes in the intraocular pressure readings obtained by MAT are significantly less than changes obtained by GAT. Numerical calculations have shown the advantage of the IntraLASIK refractive correction of hyperopia compared to the LASIK correction. Because of the fact that during the $L A S I K$ surgery the annular layer with smaller inner and outer diameters is ablated and thicker corneal flap is cut, larger deformations and displacements in the thinning region of the cornea, as well as greater decrease of the flexural rigidity of the cornea, have been observed.

Key words: intraocular pressure, hyperopia, applanation tonometry, LASIK surgery, IntraLASIK surgery.

Получено 12 мая 2015 